\title{
Role of maps and public street signs in wayfinding behaviour of foreign visitors
}

\author{
Yoshiki WAKABAYASHI $^{\mathrm{a}}{ }^{*}$, Bochra BETTAIEB $^{\mathrm{b}}$ \\ ${ }^{a}$ Tokyo Metropolitan University,wakaba@tmu.ac.jp \\ ${ }^{b}$ Tokyo Metropolitan University, bochra_bettaieb@hotmail.fr \\ * Corresponding author
}

Keywords: public signs, wayfinding, guide maps, foreign visitors, Tokyo

\begin{abstract}
:
In wayfinding behavior, maps are usually used to plan routes prior to spatial movement. People occasionally use public street signs to confirm their current position on the map and find their way. Thus, public signs can complement maps even in the age of ubiquitous mapping. Foreign visitors, in particular, tend to rely on public signs in unfamiliar environments. However, few studies in cartography and GIScience have dealt with the role of signs in wayfinding behavior and their relationship to maps. This study examined the current status of public street signs and maps and issues related to them in wayfinding behavior by foreign visitors.
\end{abstract}

We obtained data on public signs from our own fieldwork in Shinjuku District, which is one of the most popular tourism sites in Tokyo. The information displayed on 187 signs was recorded, and the locations of these signs were geocoded. Data analysis revealed that $65.7 \%$ of the signs included a map, which may be a notable feature of Japan. Within one kilometer of Shinjuku Station, public signs were unevenly distributed, and many signs were seen in the new urban area situated on the west side of the district. According to the typology of public signs (Calori and Vanden-Eynden 2015), signs with maps were classified as guiding signs. The other types are direction signs, identification signs, and regulation signs. Hence, maps on street signs can be used to identify one's current location and find one's way.

To prepare for the 2020 Olympic Games, the Tokyo metropolitan government has been promoting the widespread use of multilingual signs for foreign visitors. As a result, most of the signs that we observed in Shinjuku displayed multilingual expressions. Maps on public signs also featured pictograms and multilingual annotations. However, we found that the use of pictograms was not uniform and realized that some expressions might confuse foreigners. On the other hand, as all the maps on signs were aligned with the direction of the viewer, problems caused by the alignment effect described in previous psychology studies can probably be avoided.

Although public signs and maps on the street in downtown Tokyo sometimes cause problems for foreign visitors' wayfinding, they have undoubtedly helped in providing accurate directions through characters and pictograms. As an implication for the study of ubiquitous mapping, we can point out two roles of public signs in wayfinding behavior. First, as Klippel et al. (2010) mentioned, You-Are-Here maps are the original form and the grandmother of all location-based services (LBS). Therefore, guiding signs play a role of ubiquitous mapping in a real-world space by showing current location and direction. Second, a direction sign is an environmental cue connecting the map and the real-world space. In this case, public signs can be regarded as an annotation of actual-size maps in the real-world urban space. Thus, public signs can be replaced by LBS in the future.

\section{References}

Calori, C and Vanden-Eynden, D. 2015. Signage and wayfinding design: a complete guide to creating environmental graphic design systems (2nd Ed.). Wiley.

Klippel, A., Hirtle, S. and Davies, C. 2010. You-are-here maps: creating spatial awareness through map-like representations. Spatial Cognition \& Computation 10: 83-93. 